\title{
Vertically-aligned Silicon Carbide Nanowires as
}

\section{Metal-free Photocatalyst under Visible Light}

Jindui Hong, ${ }^{\text {a }}$ Seyyed Shayan Meysami, ${ }^{a}$ Vitaliy Babenko, ${ }^{\text {a,b }}$ Santamon Luanwuthi, ${ }^{\text {a }}$ Jesus Acapulco, ${ }^{a}$ Philip Holdway, ${ }^{\mathrm{a}}$ Nicole Grobert*a

${ }^{a}$ Department of Materials, University of Oxford, Parks Road, Oxford OX1 3PH, United Kingdom

${ }^{b}$ Present address: Centre of Advanced Photonics and Electronics, University of Cambridge, 9 JJ

Thomson Ave, Cambridge CB3 OFA, United Kingdom

*E-mail: jindui.hong@materials.ox.ac.uk; nicole.grobert@materials.ox.ac.uk 

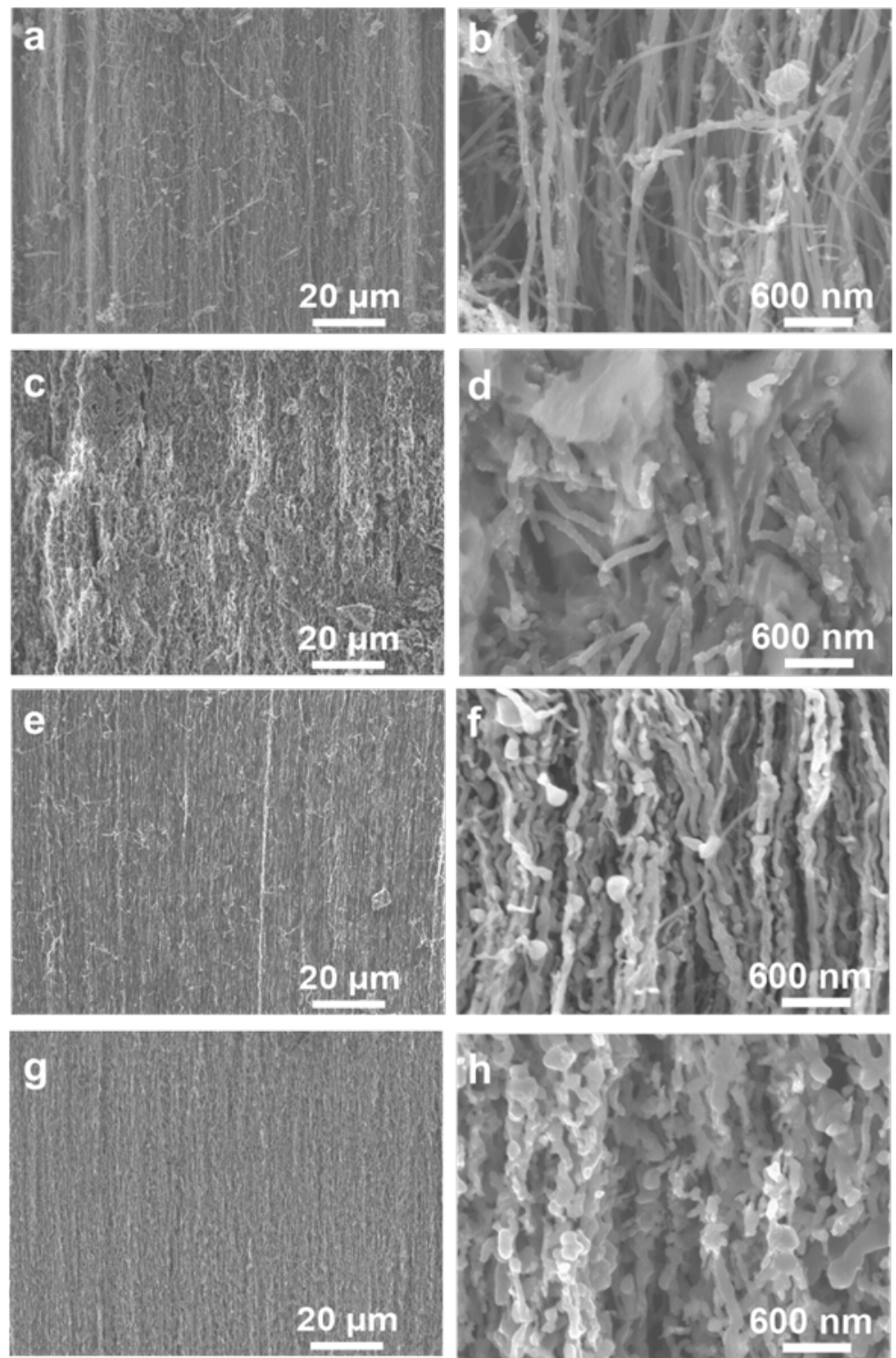

Figure S1. SEM images of (a, b) VACNTs, (c, d) $\mathrm{SiO}_{2}$-VACNTs, (e, f) VASiC/CNTs and (g, h) VASiCs showing the infiltration of $\mathrm{SiO}_{2}$ gel in VACNTs and the presence of aligned nanowires in $\mathrm{VASiC} / \mathrm{CNTs}$ and VASiCs. 

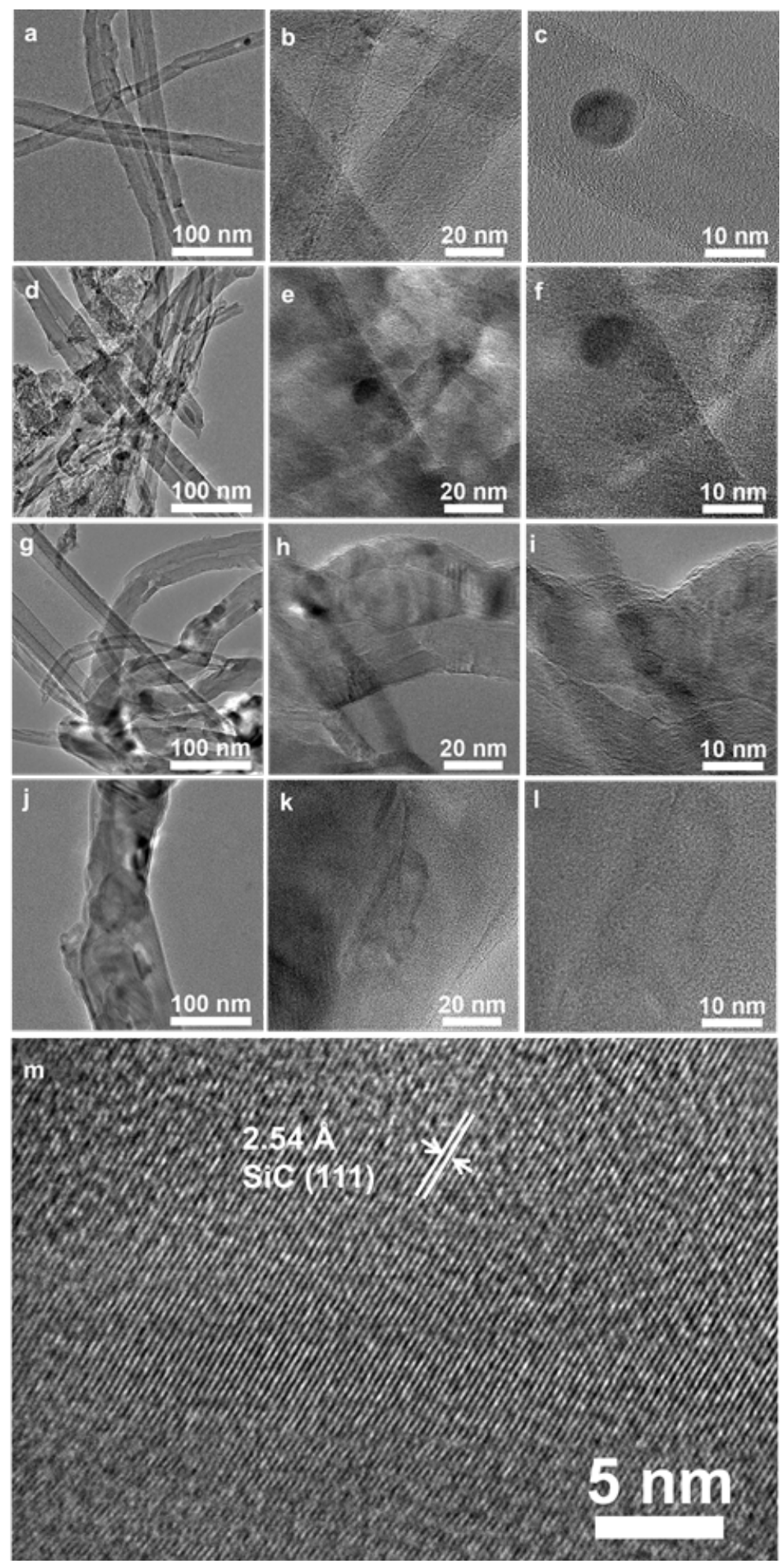

Figure S2. TEM images of (a-c) VACNTs, (d-f) $\mathrm{SiO}_{2}$-VACNTs, (g-i) VASiC/CNTs and (j-m) VASiCs showing the non-uniform and thicker diameter of VASiCs than VACNTs. 


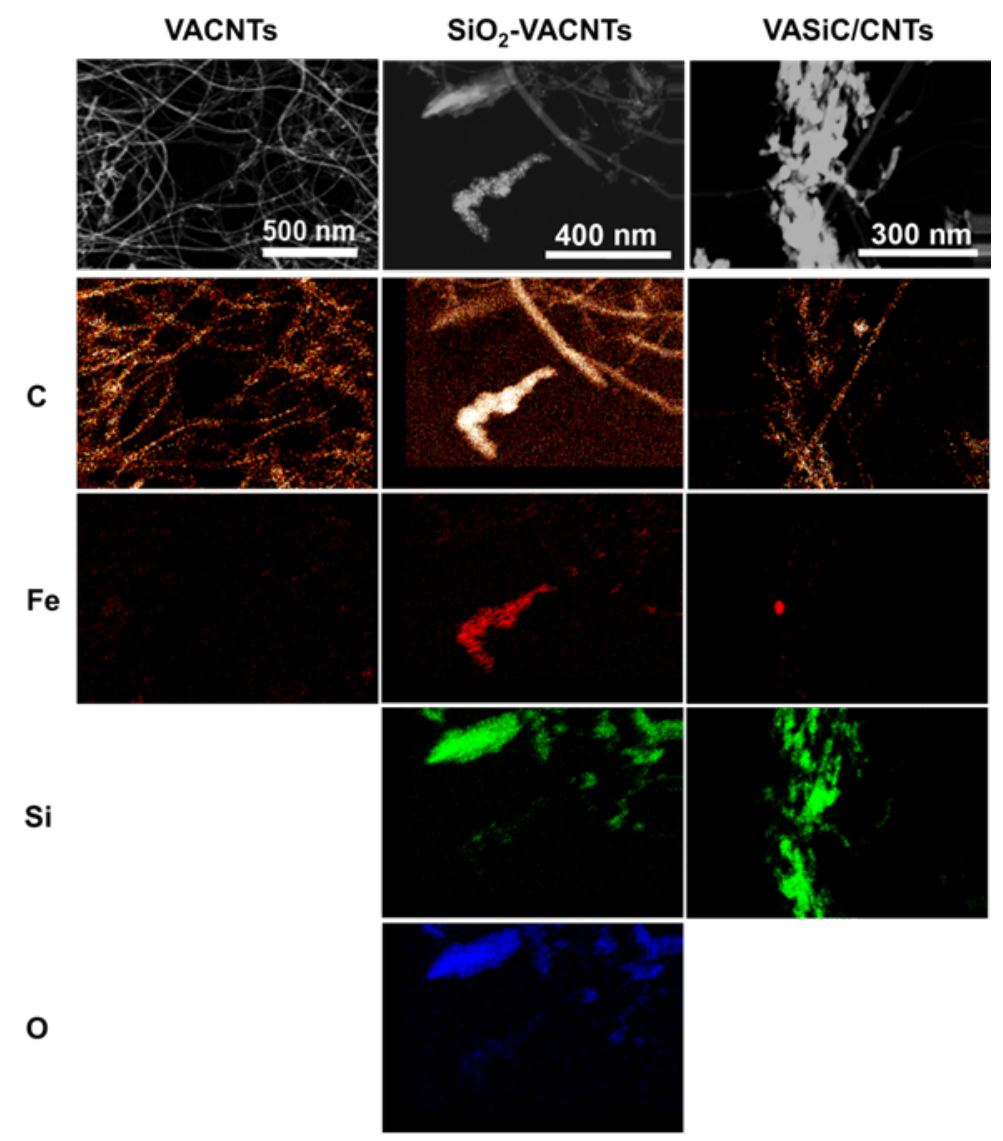

Figure S3. STEM image and EDS mapping for VACNTs, $\mathrm{SiO}_{2}-\mathrm{VACNTs}$ and $\mathrm{VASiC} / \mathrm{CNT}$ s showing the presence of $\mathrm{SiO}_{2}$ in $\mathrm{SiO}_{2}$-VACNTs and the presence of CNTs in VASiC/CNTs. C (orange), $\mathrm{Fe}$ (red), $\mathrm{Si}$ (green) and $\mathrm{O}$ (blue). 

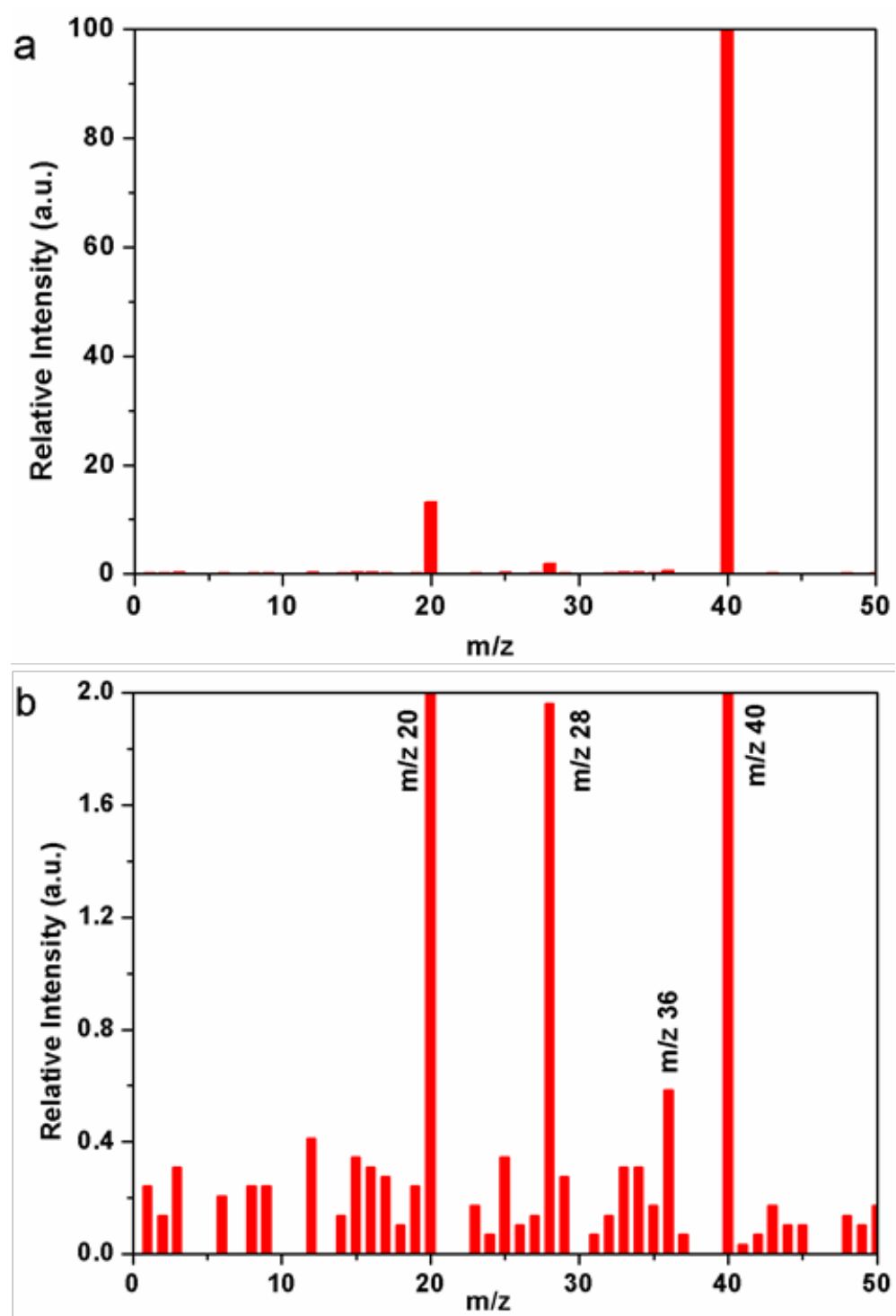

Figure S4. (a) Mass spectra of the gas residuals from the synthesis of VASiCs showing the main signal of Ar; (b) zoom-in view of the mass spectra showing signals of $\mathrm{Ar}$ and CO. m/z 20: $\left[{ }^{40} \mathrm{Ar}\right]^{2+} ; \mathrm{m} / \mathrm{z} 28$ : $[\mathrm{CO}]^{+}$; m/z 36: $\left[{ }^{36} \mathrm{Ar}\right]^{+} ; \mathrm{m} / \mathrm{z}$ 40: $\left[{ }^{40} \mathrm{Ar}\right]^{+}$. 